\title{
Optimizing environmental flow rules - a conceptual model
}

\author{
$\underline{\text { E.J. Barbour }}^{a}$, P.D. Driver ${ }^{b}$, G.A. Kuczera ${ }^{c}$, R.S. Blakers ${ }^{a}$, and B.F.W. Croke ${ }^{a}$ \\ a Australian National University, Australia, and the National Centre for Groundwater Research and \\ Training, Australia \\ ${ }^{b}$ NSW Office of Water and the Cooperative Research Centre for eWater, Australia \\ ${ }^{c}$ University of Newcastle, Australia \\ Email: emily.barbour@anu.edu.au
}

\begin{abstract}
Multi-objective optimization (MOO) is an effective and efficient method which can identify the trade-offs between different river system management options. However, a number of barriers remain between using optimization in research, and implementing it in practice. To address such limitations, this study developed a simplified conceptual model consisting of hydrologic, ecological and optimization components to explore the trade-offs between ecological and human water needs. A hypothetical catchment was used as case study, which drew on data from the Lachlan catchment in the Murray Darling Basin, Australia. The Lachlan River is highly regulated, and supports a range of conflicting water users including agriculture, urban areas and wetlands of high conservation significance.

In order to capture some of the major components of the Lachlan catchment, the hypothetical case study incorporated two major headwater storages; water users representing a spatial distribution of demands; and a 16,000 ha terminal wetland, represented in terms of wetland vegetation response (using River Red Gum (Eucalyptus camaldulensis) as an indicator species). The influence of groundwater/surface water (GW/SW) interactions on ecosystem response and optimization outcomes was examined for dry versus wet periods.

Decision variables in the optimization procedure were based on environmental flow rules and licence volumes for other water users, to explore which sets of rules achieved optimal outcomes. The objective functions consisted of maximising an ecological health score for the terminal wetland, and maximising the licence value and hence the water delivered to irrigators. A simple ecosystem response model of the wetland was developed for the purpose of this study, and consisted of a set of relationships between flow and a health score for River Red Gum.

The methodology developed demonstrates the feasibility and effectiveness of using MOO as a transparent process to explore the trade-offs between different objectives for river system planning. The conceptual model incorporates the major system complexities of conflicting water users, multiple supply storages, and $\mathrm{GW} / \mathrm{SW}$ interactions. This model is therefore adaptable to an actual representation of the Lachlan catchment, as well as to other areas. These outcomes aid in bridging the gap between use of optimization for water resource decision-making in research and in practice.
\end{abstract}

Keywords: Multi-objective optimization, environmental flows, river system management, Lachlan 


\section{INTRODUCTION}

In regulated river systems where there are numerous conflicting demands for water, a transparent process is needed to investigate ways to maximise efficient water delivery, and explore the trade-offs between water use objectives. MOO algorithms are one approach, and have been widely applied to different aspects of water management. However, a large proportion of previous studies simplify a multi-objective problem to a single objective (e.g. Shiau, 2009), and there are minimal examples where MOO has been used in conjunction with a combined river system model and ecosystem response model to develop suitable environmental flow rules. Studies which have considered both ecological and human water objectives have generally defined these objectives at the point of release from storages (in-stream targets), and have not explored the requirements of ecological assets further downstream (e.g. Dittmann et al., 2009).

A number of barriers to the implementation of $\mathrm{MOO}$ in practice have been identified, including model run times balanced against incorporation of an appropriate level of complexity, and effective demonstration of the role of optimization in aiding the decision making process.

This paper aims to overcome some of these identified barriers by using a conceptual model to explore:

1. What type of environmental flow rule(s) have the optimal environmental outcome; and

2. What are the trade-offs between meeting objectives for the environment and for other water users.

In doing so, the paper examines how MOO can be applied to answer such questions, focusing specifically on:

a) Formulation of the river system model

b) Formulation of the optimization problem

The conceptual model uses a hypothetical case study based on information from the Lachlan catchment in the Murray Darling Basin (MDB), Australia. The purpose of the model was to demonstrate the potential benefits of using multi-objective optimization and provide guidance for model formulation. The model does not in any way reflect the actual operation of the Lachlan system, and the results are for demonstration only.

\section{CONCEPTUAL MODEL}

\subsection{River System Model}

The hypothetical catchment was built using the Integrated Quantity and Quality Model (IQQM) (Hameed and Podger, 2001), and included the following key components (Figure 1):

- Major control structures (headwater storages)

- Different types of water users (irrigators, town water supply, the environment)

- Spatial distribution of users

- $\mathrm{GW} / \mathrm{SW}$ interactions

- Other major physical processes (tributary inflows, losses, river routing)

Whilst there are two main headwater storages in the conceptual model, Dam 2 has little influence on the system compared with the Dam 1, being much smaller and only providing for orders upstream of the confluence. The town water supply node is based on a fixed monthly demand pattern, which is of substantially less volume compared with the irrigator demands included in the model. The irrigator demands vary over time based on the percentage allocation (the volume of water for each unit of licence which is updated during the season), estimated available water, and the irrigator's risk function. Detail on the model formulation for the terminal wetland and groundwater recharge is discussed below.

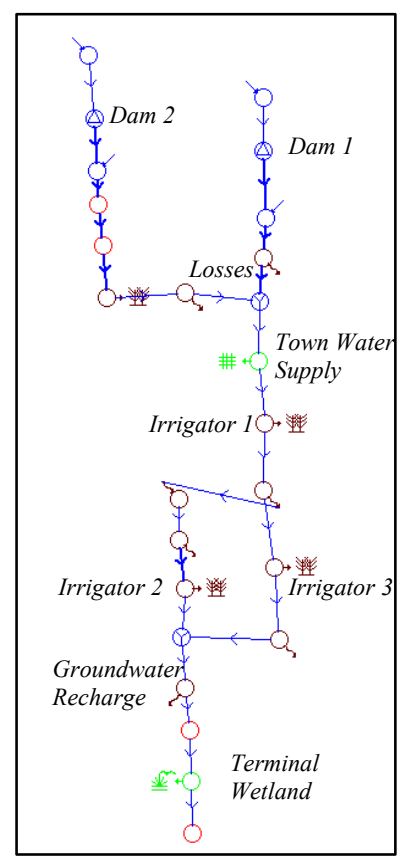

Figure 1. IQQM conceptual model

The model was run over two periods to compare system behaviour during both dry and wet years, and the impact this has on the system objectives. For the dry period, the model was run from 1 January 2001 to 31 July 2006 using a daily time step, and for the wet period from 1 January 1959 to 31 July 1964. These periods were the longest within the flow record (1898-2006) which contained consecutive dry or wet years respectively, determined using a flow duration curve (with the exception of 1962, which fell into the middle $33 \%$ of flows). Initial storage volumes for Dams 1 and 2 were those used as initial conditions in the Lachlan 
IQQM model. These represent 27 and $12 \%$ of the full capacity respectively. These low volumes were used to test the ability of the optimizer to find trade-off solutions under limited water supply, given that only a small proportion of the actual demands have been included in the conceptual model.

\subsection{Groundwater Component}

GW/SW interactions have been included given they can influence system operations, both in terms of estimated surface water losses and in potentially sustaining deep rooted vegetation during periods of low flows. The following analysis is based on data for the terminal wetland of the Lachlan, the Great Cumbung Swamp (GCS), and was used for the terminal wetland in the hypothetical case study. The GCS is underlain by four main aquifer formations, of which the upper aquifer (Coonambidgil Formation) has shown strong interactions with surface water (Brady et al., 1998; Driver et al., 2004).

The focus of the groundwater analysis for this study was to incorporate into the optimization model an estimate of the volume of water infiltrating to groundwater, as well as an estimate of changes in groundwater level over time. The latter component was then used to predict the likelihood of River Red Gum having access to groundwater during dry periods. River Red Gum was examined due to its potential to utilise groundwater during drought (Thorburn and Walker, 1994). Whilst three different sources of groundwater data were examined, the study focused on data from a single bore (GW036721) as it covered the longest time period with the most data points. GW036721 included intermittent observations of groundwater levels from October 1987 to March 2010, collected at frequencies varying from approximately 2 months to over 2 years. During periods of high surface flow the monitoring site was inundated, preventing the collection of groundwater depths at these times.

Pearson's correlation coefficient was used to measure the relationship between time series of groundwater levels and stream flow, where the stream flow data was adjusted using the cumulative departure from the mean. Details on the cumulative flow departure method can be found in Blakers et al. (2011). Groundwater levels from bore GW036721 were found to be highly correlated with flows upstream of the GCS.

Given that GW measurements were relatively infrequent, GW depths for the remainder of the modelling period were estimated by forming a relationship with surface flow upstream of the GCS. It was assumed that GW depth is influenced by SW flows which occurred during previous time steps, and to a lesser extent the flow during the current time step. This is due to the delay in response between GW and SW, as well as the effect of previous flows in determining infiltration rates, lateral flows, and uptake by vegetation (i.e. wet $\mathrm{v}$ dry antecedent conditions). A simple relationship was therefore derived for the purpose of demonstrating $\mathrm{SW} / \mathrm{GW}$ interactions in an optimisation case study. The relationship is comprised of two components:

a) Applying a daily linear auto regressive model to the surface water data upstream of the GCS, to incorporate antecedent conditions into daily flow values.

b) Fitting a function to relate observed groundwater levels with adjusted flow values.

The auto regressive model was used to adjust the surface water data to give a greater weighting to previous flows compared with flow for the current time step. The model takes the form:

$$
\begin{array}{llll} 
& & \tilde{Q}_{i}=a \tilde{Q}_{i-1}+(1-a) Q_{i} \\
\text { Where: } & \tilde{Q} & = & \text { adjusted flow } \quad a=e^{-\frac{1}{\tau}} \\
& \tau & = & \text { flow } \quad
\end{array}
$$

Equation 1 therefore adjusts the current flow by combining it with that of the adjusted flow from the previous time step. The parameter $a$ influences the relative weight given to previous flows compared with the current time step, and is an exponential function using a value for $\tau$.

An inverse exponential function (Equation 2) was then used as a non-linear relationship between adjusted flow values and observed groundwater levels. The function was calibrated using available data.

$$
G W_{\text {depth }, i} \approx \frac{(a-b)}{1+e^{-\lambda\left(\widetilde{Q}_{i}-\widetilde{Q}_{\text {mid }}\right)}}+b
$$

where

$\begin{array}{ll}G W_{\text {depth }} & = \\ a & = \\ b & = \\ \lambda & = \\ \tilde{Q}_{\text {mid }} & =\end{array}$

groundwater depth

-15.5 (lower asymptote (lowest possible groundwater depth))

-11.5 (upper asymptote (highest possible groundwater depth))

-0.01 (slope of curve)

430 (value of $\tilde{Q}$ at the inflection point) 
This equation was developed with the focus of incorporating groundwater into the conceptual model. Further analysis would be required to develop a more accurate model of GW/SW behaviour.

Given that losses are represented in IQQM using a surface water flow/loss relationship, losses to groundwater were estimated by deriving a relationship between monthly SW flow and monthly change in groundwater volume. It was assumed that change in GW volume is primarily due to infiltration, and hence can be estimated using daily groundwater depths and the approximate inundation area of the GCS from Driver et al. (2004). For the purpose of this study, it was assumed that the area of recharge is approximately equal to that of the shallow underlying aquifer. A simple linear relationship was then derived for dry and wet years separately, given that higher rates of loss are expected during dry years.

$$
\begin{aligned}
& \Delta G W_{\text {vol }}^{\text {dry }}(30 \text { days })=0.0213 \sum_{i-30}^{i} Q_{i}-827 \\
& \Delta G W_{\text {vol }}^{\text {wet }}(30 \text { days })=0.0484 \sum_{i-30}^{i} Q_{i}-881
\end{aligned}
$$

\subsection{Terminal Wetland - Environmental Response}

As an initial test for the conceptual model, a simple environmental response model was developed based on published water requirements for River Red Gum (Rogers and Ralph, 2010). The model calculated an ecological health score by comparing the flow received at the terminal wetland, with the published water requirements for duration, magnitude and rate of change of flow. A score of 1 was assigned when the received flow met required conditions; 0 when the appropriate inter-flood duration requirement was being met, and a value of between 0 and -1 outside these. During extended dry periods, the score was approximated based on the

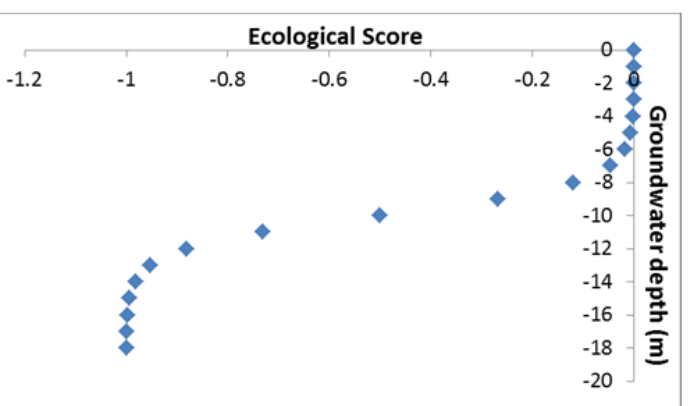

Figure 2. Ecological health score during drought based on possible access to groundwater. likelihood of access to groundwater (Figure 2). The relationship between groundwater level and response was estimated as follows:

$$
\text { where } \quad H \quad=\quad \begin{array}{ll}
H=e^{-\left(G W_{\text {depth }}+10\right)} & \text { ecological health score }
\end{array}
$$

Published values vary for maximum depths at which River Red Gum can access groundwater. This is likely due to individual differences as well as the effect of soil type and rate of change in groundwater levels, where levels may drop faster than the rate of root growth (Cunningham et al, 2011). Based on papers cited, a threshold depth of 10m was used in Equation 5, as a possible depth at which there is decreasing likelihood of access by River Red Gum roots (Canadell et al, 1996; Cunningham et al., 2011). This depth is also consistent with observed groundwater levels (between 11.8 and $14.7 \mathrm{~m}$ below ground for GW036721) and observed spatial distribution of river red gums.

\section{FORMULATION OF THE OPTIMIZATION PROBLEM}

\subsection{Objective Functions}

Two different scenarios were used to explore the effect of different objective functions on the optimal solutions. The first of these used two objectives, which were to maximise (1) the sum of environmental response scores for each time step $(\mathrm{H})$ for the wetland, and $(2)$ the total water diverted to all irrigators. The second scenario used three objective functions, and included the same environmental objective as well as the total diversion for Irrigator 1, and thirdly the total diversion for Irrigators 2 and 3 combined.

It is noted that this is a simplistic representation of potential objective functions, which should take into account diversions and ecosystem health throughout the model period as well as total diversions and total health score. The focus of these objective functions was to examine the trade-offs between users and the effect of combining objectives. Each of the two scenarios was also run for wet and dry periods, to examine the impact of antecedent conditions on management outcomes.

\subsection{Decision variables}

The focus of the conceptual model was to develop optimal environmental flow rules. Given the existing limited flexibility in modelling environmental flow rules in IQQM, this paper focused on exploring different 
components of a simple translucency rule, which is one of the three types of planned environmental flow rules for water quantity for the Lachlan. The purpose of translucency is to enable a proportion of dam inflows to be released, based on various initial conditions. In this case, a simple translucency rule was defined using four decision variables: a lower and upper threshold for inflows to Dam 1, and the start and end month for which the rules would apply. It should be noted this rule is far simpler than the actual Lachlan translucency rule, which was derived based on expert knowledge and stakeholder input. In this case study, translucency operated as follows: during the specified start and end month, if inflows are less than the lower threshold, no environmental release occurs. Once the inflow is between the lower and upper threshold, the entire inflow is released as an environmental release. When inflows exceed the upper threshold, an environmental release equal to this upper threshold is made (Podger and Hameed, 2000).

An additional three decision variables were used to allow the licence for each irrigator to be varied. Of the three irrigators, Irrigator 1 has the largest maximum potential licence volume, followed by Irrigator 2 and finally Irrigator 3.

\subsection{Optimization algorithm}

The multi-objective genetic algorithm eMOGA (Laumanns et. al., 2002) was used as the optimizer for the conceptual model. A wrapper was developed which allowed eMOGA to interface with IQQM. eMOGA was chosen based on ability to find a diversity of solutions along the Pareto front with reasonable convergence time. However, it should be noted that no evolutionary algorithm can guarantee finding the exact Paretooptimal solutions, but rather aims to find near optimal solutions. These can still provide significant improvement over current operational rules. The eMOGA parameters used were: population size of 100, maximum number of generations of 2500, probability of crossover and mutation of 1.0 and 0.025 respectively. 2500 generations were used to minimise the computation time, in order to investigate different scenarios. It is likely that a larger number of generations would improve convergence, and potentially increase the number and diversity of solutions along the Pareto front. The following results are therefore provided in the context of investigating the conceptual model, and may be further improved upon with more generations.

\section{RESULTS AND DISCUSSION}

The results from the conceptual model indicated that increases in ecological score can be achieved with relatively small changes in total irrigation diversion (analogous to reduced licence volumes) (Figure 3a). For example, the environmental score was doubled from 34 to 68 by decreasing the total irrigator diversion by $<2 \%$. This outcome is consistent with that found by Dittmann et al (2009), where a small reduction in water supply to extractive users achieved an improved match between releases and natural flows. The relative trade-off between objectives also varies along the curve. For example, once the environmental score increases above 120, there is a greater reduction in total diversions compared with changes in lower environmental scores.

When the total diversion for Irrigator 1 is combined with that for Irrigators 2 and 3 in the 3 objective scenario, it can be seen from Figure 3(a) that a similar outcome is obtained compared with that of the 2 objective scenario. However, there are some differences for higher environmental scores, suggesting that maximising diversions for Irrigator 1 separately can result in lower total diversions for all irrigators at the same environmental score. It is also possible that these differences are a result of insufficient solution convergence. The trade-off between all 3 objectives can be seen in Figure 3(b), where high environmental scores combined with high Irrigator 1 diversions are associated with lower diversions for Irrigators 2 and 3.

Focusing on the 2 objective scenario, the licence volume for the three irrigators also had different effects on the total environmental health score (Figure 3c). Irrigator 1 had a relatively small impact (all decision variable values were $>90 \%$ of the possible maximum licence volume), whereas licence volumes of $>80 \%$ for Irrigator 3 had a higher chance of resulting in a reduction in environmental score. The environmental score was relatively insensitive to Irrigator 2's licence volume except for high environmental scores of $>150$. However, there are a limited number of data points from which these conclusions can be drawn.

The highest environmental score was achieved when the translucent release was applied all year, followed by May to February (inclusive), July to February, and then July to March. As expected, the highest total diversion occurred when there was the smallest translucency window, of October/November to January. A translucency window of approximately 180-2200 ML/d achieved the highest environmental scores. Both the environmental score and total irrigator diversion were relatively insensitive to both lower and upper thresholds, except for the lowest environmental scores. 
Comparing optimal solutions for dry and wet periods, significantly higher environmental scores were achieved during the wet period given the increased water availability (Figure 4d). For the 2 objective scenario, all decision variables for these optimal values had translucency operating for all months of the year, with a lower flow threshold of 146-155ML/d and an upper threshold of $9800-10100 \mathrm{ML} / \mathrm{d}$. However, a greater proportion of solutions had lower total irrigator diversions compared with the dry period. Only four solutions were found where the total diversion was greater than $140 \mathrm{GL}$ for the wet scenario, compared with all but one solution being greater than $140 \mathrm{GL}$ for the dry scenario. It is possible that this is due to the optimizer having insufficient solution diversity to find the full Pareto front, or having not converged. When Irrigator 1 diversions were added to those of 2 and 3 in the 3 objective scenario, similar results were obtained for high total diversions. The additional objective values shown for lower total diversions indicate the effect of maximising Irrigators 2 and 3 separately. These irrigators have a lower combined maximum diversion compared with Irrigator 1, and hence high objective values for Irrigators 2 and 3 resulted in a lower total diversion for all three irrigators.

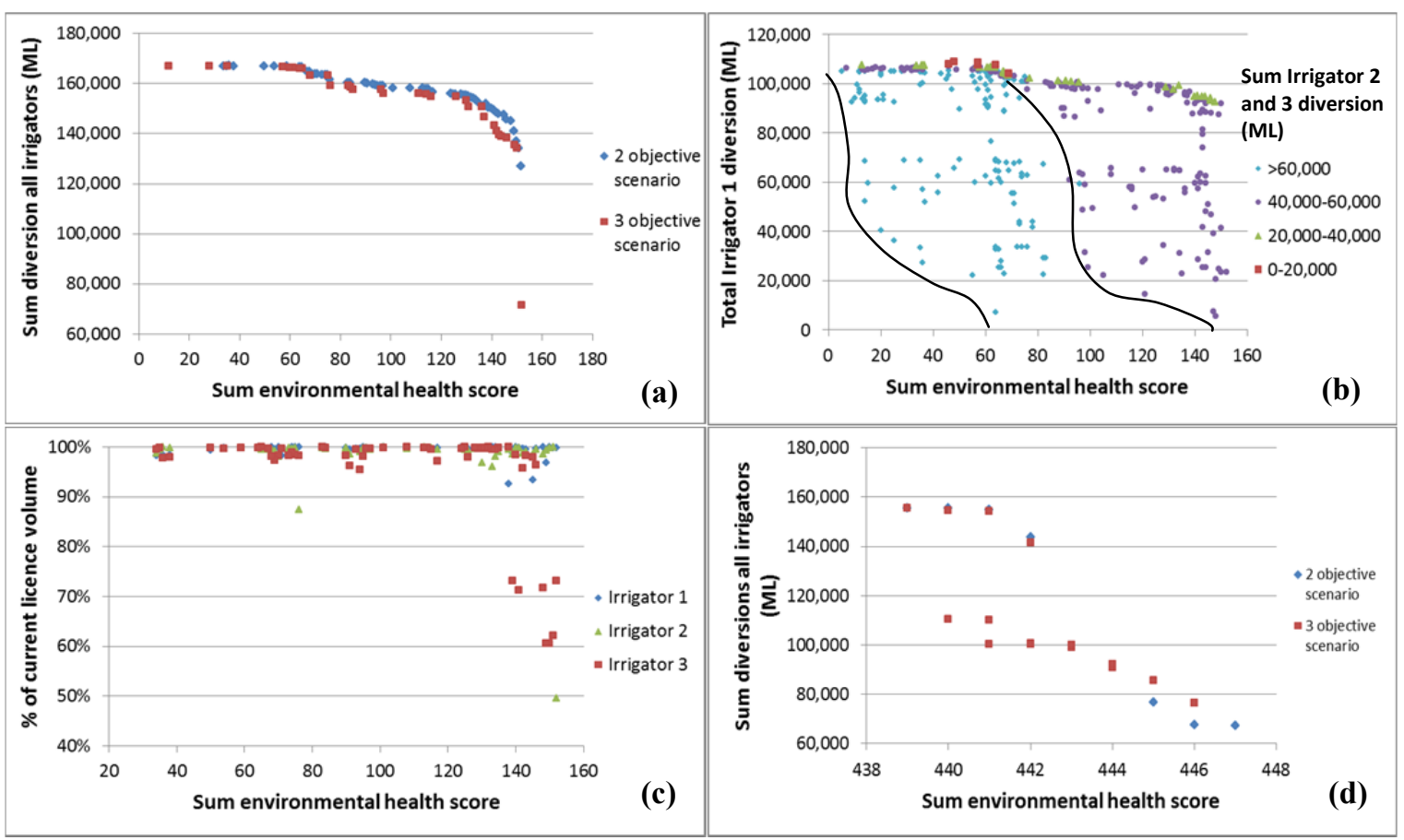

Figure 3. Trade-off between total environmental health score and irrigator diversions showing (a) comparison between scenarios (dry); (b) trade-offs for the 3 objective scenario (dry); (c) effect of irrigator licence volumes on environmental objective function (dry); and (d) comparison between scenarios (wet).

\section{CONCLUSIONS AND RECOMMENDATIONS}

MOO has been successfully applied to a river system model which incorporates environmental and other water user objectives, as well as the effect of GW/SW interactions. The conceptual model indicates the potential to improve environmental outcomes with minimal impact on other water users, and determine which management decisions can have the greatest effect. Using MOO also assists in communicating the trade-offs between objectives, although visualisation can become problematic where more than 3 objective functions are used.

Although the structure of the environmental flow rule has been predefined as a type of translucency rule, MOO can determine the components of this rule which have the best outcome for all objectives, and which components have the most impact on objectives. Comparing wet and dry periods, it is evident that there are substantial differences in the optimal decision variables and objective values. This reinforces the need to develop adaptable environmental flow rules.

This study has identified a number of areas recommended for future work, which are summarised as follows:

- The collection of additional groundwater data to improve the accuracy of the current analysis, and improve the representation of processes such as the response times to surface water.

- Additional investigation into the likelihood of groundwater being accessed by vegetation in the terminal wetland (e.g. Driver et al., this congress), using techniques such as remote sensing. 
- Improvement of the ecological response model, to include more species, more varied responses, and to account for semi-permanent/permanent changes in ecosystem behaviour. The model would also be improved by including site specific data, although this information is still relatively limited.

- Extensions to IQQM to enable external functions to be linked, providing greater flexibility to explore different types of environmental requirements, rules and responses.

- Greater investigation of the effect of different types of objective functions and decision variables, particularly in providing more adaptable environmental flow rules.

- Sensitivity analysis of both river system and optimization parameter values.

Despite these limitations, the conceptual model discussed in this paper demonstrates the potential of MOO, to assist in the exploration of optimal environmental flow rules, and the trade-off between objectives.

\section{ACKNOWLEDGEMENTS}

The authors would like to gratefully acknowledge the NSW Office of Water for providing access to the Lachlan IQQM model and GCS data. The authors also thank Joseph Cairns (NSW Office of Water) for assistance in data provision, and the reviewers for their valuable feedback on the draft paper.

\section{REFERENCES}

Blakers, R., Kelly, B., Anderssen, R., Mariethoz, G., and Timms, W. (2011). 3D dendrogram analysis for mapping aquifer connectivity and flow model structure. In Proceedings of MODFLOW and More 2011: Integrated Hydrologic Modeling, Colorado School of Mines, June 5-8, 2011, 236-240.

Brady, A., Shaikh, M., King, A., Ross, J., and Sharma, P. (1998). The Great Cumbung Swamp: Assessment of Water Requirements. Department of Land and Water Conservation, Centre for Natural Resources, Ecosystem Management Branch, NRMS Project R-5048.

Canadell, J., Jackson, R., Ehleringer, J., Mooney, H., Sala, O., and Schulze, E. (1996). Maximum rooting depth of vegetation types at the global scale. Oecologia, 108(4), 538-595.

Cunningham, S., Thomson, J., Mac Nally, R., Read, J., and Baker, P. (2011). Groundwater change in forecasts widespread forest dieback across an extensive floodplain system. Freshwater Biology, 56(8), 1494-1508.

Dittmann, R., Froehlich, F., Pohl, R. and Ostrowski, M. (2009). Optimum multi-objective reservoir operation with emphasis on flood control and ecology. Natural Hazards and Earth Sciences, 9(6), 1973 - 1980.

Driver, P., O'Rourke, M., Robinson, M., Jones, J., Raisin, G. and Wettin, P. (2004). Great Cumbung Swamp Water Balance Assessment. Final Report. NSW Department of Infrastructure, Planning and Natural Resources.

Driver, P. D., Barbour, E. J., and Michener, K. (this congress). An integrated surface water, groundwater and wetland plant model of drought recovery and response for environmental water management. In MODSIM 2011 International Congress on Modelling and Simulation, Modelling and Simulation Society of Australia and New Zealand.

Hameed, T. and Podger, G. (2001). Use of IQQM simulation model for planning and management of a regulated river system. IAHS Red Book, 83-89.

Labadie, J. W. (2004). Optimal operation of multireservoir systems: state-of-the-art review. Journal of Water Resources Planning and Management, 130(2), 93-111.

Laumanns, M., Thiele, L., Deb, K., and Zitzler, E. (2002). Combining Convergence and Diversity in Evolutionary Multiobjective Optimization. Evol. Comput. 10, 263-282.

Nicklow, J., Reed, P., Savic, D., Dessalegne, T., Harrell, L., Chan-Hilton, A., Karamouz, M., Minsker, B., Ostfeld, A., Singh, A. and Zechman, E. (2010). State of the art for genetic algorithms and beyond in water resources planning and management. Journal of Water Resources Planning and Management, 136(4), 412 - 432.

Podger, G. and Hameed, T., (2000). Use of IQQM to develop environmental flow rules for the Lachlan regulated river system, 3rd International Hydrology and Water Resources Symposium of the IE Aust, Perth, WA.

Rogers, K. and Ralph, T.J. (2010). Floodplain wetland biota in the Murray-Darling Basin: water and habitat requirements. CSIRO Publishing, Collingwood, Australia.

Shiau, J. T. (2009). Optimization of Reservoir Hedging Rules Using Multiobjective Genetic Algorithm. Journal of Water Resources Planning and Management-Asce, 135(5), 355-363.

Thorburn, P. and Walker, G. (1994). Variations in stream water uptake by Eucalyptus camaldulensis with differing access to stream water. Oecologia, 100(3), 293-301 